\title{
Simulation as a Multidisciplinary Team Approach in Healthcare Programs in an Urban University Setting
}

\author{
Dawn I. Blue ${ }^{1}$, Geraldine C. Fike ${ }^{1}$, Guillermo Escalante ${ }^{2}$, Yeon Kim ${ }^{1}$, José A. Muñoz ${ }^{3}$ \\ ${ }^{1}$ Department of Nursing, California State University San Bernardino, California, USA \\ ${ }^{2}$ Department of Kinesiology, California State University San Bernardino, California, USA \\ ${ }^{3}$ Department of Sociology, California State University San Bernardino, California, USA \\ Correspondence: Dawn Blue, 5500 University Parkway, San Bernardino, CA, 92407, USA.
}

Received: November 5, 2018

Accepted: November 20, 2018

Available online: November 29, 2018

doi:10.11114/ijsss.v6i12.3749

URL: https://doi.org/10.11114/ijsss.v6i12.3749

\begin{abstract}
Background: In the hospital setting, patients are usually cared for by a nurse and multidisciplinary teams which may include physical therapists, social workers, and public health workers. However, students in health care programs usually will not experience interdisciplinary scenarios developing needed skills. Combining classes and replacing certain curriculum activities with patient simulation projects that include several departments may improve their educational experience and success. Simulation is technology used to enhance instruction resources for all students. Simulation not only captures the attention of the video-game generation but actively engages students in the learning process. Simulation can be a valuable experience to keep students actively involved in learning by offering the opportunity to apply knowledge learned to the clinical setting, thus making it real. It is compelling to consider the impact of simulation in increasing the competency of students when they are in the work force while decreasing error rate and impacting the quality of care.
\end{abstract}

Methods: A mixed method approach involved simulation experience followed by data collection via survey.

Results: Students across all disciplines reported increased ability for collaboration and communication.

Conclusions: Demonstrated the value of introducing the students to teamwork and collaboration experiences via simulation.

Keywords: simulation, interdisciplinary, academic, collaboration, teamwork

\section{Introduction}

This project took a collaborative approach to produce patient simulation technology experiences. Although, needed skills are learned within the walls of the university they remain in silos. Combining classes and replacing certain curriculum activities, with patient simulation projects that includes several departments will enhance student access across the institution, while improving the educational experience and success. Examining the effects of innovative simulations can provide enhanced training for student's use of technology in support of active learning while remaining positively engaged in their education.

Hospitalized patients are typically cared for by a nurse and multidisciplinary teams which may include physical therapists, social workers, and public health workers yet students in health care programs usually will not experience necessary scenarios developing needed skills. This research was conducted for use by faculty and students. Our goal is was to depict simulation to be a valuable experience to keep students actively involved in learning by offering the opportunity to apply knowledge to the clinical setting, thus making it real.

As part of our project we provided several scenarios for our participants. During the scenarios, the students care for the patient, by assessing the situation and implementing interventions using critical thinking. Faculty members serve as facilitators to observe, provide cues, and guide the experience, but not as a participant. Simulation experiences are comprised of a scenario and debriefing. As addressed in the literature debriefing sessions should occur immediately after the simulation is completed so the thoughts and feelings are fresh in the participants mind. Active debriefing facilitated by the educator, should challenge the student to reflect on their actions and clinical judgment (Jeffries, 2007). 
The effectiveness of simulation has been a method for instruction across several disciplines. Industries with known hazards have experienced amazingly small failure rates when simulation was implemented. Simulation has been used in aviation since the early 1900's (McNeal, 2010).

Beginning with Sim One, the medical profession started using simulation to train anesthesiologists. It soon was adapted to other areas of medicine (Bradley, 2006). Nursing education began to start using simulation in the 1990's and according to a study by the National Council of State Boards of Nursing (2014), it was shown that using simulation for up to $50 \%$ of the clinical experience is as effective as bedside patient care (Hayden, Smiley, Alexander, Kardong-Edgren, $\&$ Jeffries, 2014).

Sociology and social studies scholars have developed their own simulation projects and reflected on this particular pedagogical approach through critical reviews of the practice (Bramesfeld \& Good, 2015; Brown, 2015; Casper \& Morrison, 2010; Dorn, 1989; Fisher, 2008; King \& Cazessus, 2008; Lovell-Troy, 1989; Norris, 2013). According to Dorn, (1989) one of the overarching themes that emerge from the sociology and social studies literature is that simulations provide direct experience, relieve class time woes, and demand full participation from participants. Dorn (1989) has argued that simulations provide for enhanced cooperation, interaction, and communication between students and from a sociological perspective provide a space for understanding group processes such as those found in health institutions.

\section{Method}

A total of 44 volunteer students $(15=$ males, $28=$ females, $1=$ no answer; age $=23.8+/-4.8$ years; Grade Point Average, $(\mathrm{GPA})=3.55+/$ - 0.35) from majors in nursing, kinesiology, sociology, and psychology participated in four multidisciplinary simulation exercises over the course of an academic quarter. The goal of the study was to increase communication in a team environment and increase while expanding the usage of simulators in nursing and non-nursing programs. A total of $66 \%(n=29)$ were nursing majors, $18 \%(n=8)$ were kinesiology majors, $9 \%(n=4)$ were sociology majors, and 7\% ( $\mathrm{n}=3)$ were psychology majors. Tables 1 and 2 demonstrate the frequencies of student responses to the survey.

The project included a mixed method approach for collecting data. The participants were asked for qualitative open responses. For the simulation study 44 students provided free responses to the debriefing questions provided by project leaders. As part of our project, the researchers reviewed these students' observations and attitudes about their participation experience. The survey responses were provided following the debriefing session. Institutional Review Board permission was obtained from the university. All participants signed informed consent.

\section{Results}

The quantitative portion of the study involved employing descriptive statistics and chi-square tests of our data. Data analysis was performed using the software, Statistical Package for the Social Sciences (SPSS) version 24 (IBM Corporation, 2016) with an alpha level set at $\mathrm{p} \leq 0.05$ and NVivo qualitative data analysis Software; (QSR International Pty Ltd. Version 11, 2012). Chi-square tests were run for academic major and overall GPA, sex and GPA, students feeling responsible for their own learning and GPA, and students feeling the instructor is responsible for telling them what they need to learn and their GPA.

Table 1. Satisfaction with Current Learning

\begin{tabular}{lcccc}
\hline \multicolumn{1}{c}{ Question } & $\begin{array}{l}\text { Strongly } \\
\text { Agree }\end{array}$ & Agree & Undecided & $\begin{array}{c}\text { Disagree } \\
\text { Strongly } \\
\text { Disagree }\end{array}$ \\
\hline Effective teaching methods in simulation & $\begin{array}{l}93.2 \% \\
(\mathrm{n}=41)\end{array}$ & $4.6 \%(\mathrm{n}=2)$ & $\begin{array}{c}2.2 \% \\
(\mathrm{n}=1)\end{array}$ & 0 \\
Simulation promotes learning & $\begin{array}{l}88.6 \% \\
(\mathrm{n}=39)\end{array}$ & $\begin{array}{c}11.4 \% \\
(\mathrm{n}=5)\end{array}$ & 0 & 0 \\
Enjoyed how instructor taught simulation & $\begin{array}{l}84.1 \% \\
(\mathrm{n}=37)\end{array}$ & $6.8 \%(\mathrm{n}=3)$ & $\begin{array}{c}9.1 \% \\
(\mathrm{n}=4)\end{array}$ & 0 \\
Teaching materials in simulation helpful & $\begin{array}{l}79.6 \% \\
(\mathrm{n}=35)\end{array}$ & $\begin{array}{c}20.5 \% \\
(\mathrm{n}=9)\end{array}$ & 0 & 0 \\
Instructor taught simulation suitable to how I learn & $\begin{array}{l}86.1 \% \\
(\mathrm{n}=37)\end{array}$ & $\begin{array}{l}11.6 \% \\
(\mathrm{n}=5)\end{array}$ & $\begin{array}{l}2.3 \% \\
(\mathrm{n}=1)\end{array}$ & 0 \\
\hline
\end{tabular}


Table 2. Self-Confidence in Learning

\begin{tabular}{|c|c|c|c|c|c|}
\hline Question & $\begin{array}{c}\text { Strongly } \\
\text { Agree }\end{array}$ & Agree & Undecided & Disagree & $\begin{array}{l}\text { Strongly } \\
\text { Disagree }\end{array}$ \\
\hline Confident mastering content of simulation & $\begin{array}{l}36.4 \% \\
(\mathrm{n}=16)\end{array}$ & $59.1 \%(n=26)$ & $\begin{array}{l}2.3 \% \\
(\mathrm{n}=1)\end{array}$ & $\begin{array}{l}2.3 \% \\
(\mathrm{n}=1)\end{array}$ & 0 \\
\hline Confident simulation covered critical content & $\begin{array}{l}77.3 \% \\
(\mathrm{n}=34)\end{array}$ & $20.45 \%(n=9)$ & 0 & $\begin{array}{l}2.3 \% \\
(\mathrm{n}=1)\end{array}$ & 0 \\
\hline $\begin{array}{l}\text { Confident developing skills and developing } \\
\text { knowledge }\end{array}$ & $\begin{array}{l}77.3 \% \\
(\mathrm{n}=34)\end{array}$ & $20.45 \%(n=9)$ & $\begin{array}{l}2.3 \% \\
(\mathrm{n}=1)\end{array}$ & 0 & 0 \\
\hline Instructors helpful resources for simulation & $\begin{array}{l}79.6 \% \\
(\mathrm{n}=35)\end{array}$ & $15.9 \%(n=7)$ & $\begin{array}{l}4.6 \% \\
(n=2)\end{array}$ & 0 & 0 \\
\hline Student responsible for learning in simulation & $\begin{array}{l}77.3 \% \\
(\mathrm{n}=34)\end{array}$ & $20.45 \%(n=9)$ & $\begin{array}{l}2.3 \% \\
(\mathrm{n}=1)\end{array}$ & 0 & 0 \\
\hline $\begin{array}{l}\text { Know how to use simulation activities to learn } \\
\text { important aspects }\end{array}$ & $\begin{array}{l}68.2 \% \\
(\mathrm{n}=30)\end{array}$ & $29.6 \%(n=13)$ & $\begin{array}{l}2.3 \% \\
(\mathrm{n}=1)\end{array}$ & 0 & 0 \\
\hline $\begin{array}{l}\text { Instructor is responsible for telling me what I need to } \\
\text { learn }\end{array}$ & $\begin{array}{l}52.3 \% \\
(\mathrm{n}=23)\end{array}$ & $15.9 \%(n=7)$ & $20.45 \%(n=9)$ & $9.1 \%(n=4)$ & $\begin{array}{l}2.3 \% \\
(\mathrm{n}=1)\end{array}$ \\
\hline
\end{tabular}

There was a significant difference between academic major and overall GPA ( $p=0.030)$, but no differences were noted between sex and GPA $(p p=0.266)$. There was also no association between GPA and students feeling they are responsible for their own learning during a simulation ( $\beta p=0.408$ ) or between GPA and students feeling the instructor is responsible for telling them what they need to learn in a simulation ( $\mathrm{p} p=0.539)$.

Three themes emerged from qualitative analysis student survey responses. First, the students gained insight into "real practice" by applying concepts learned in the classroom. Secondly, the learning took place in a "specific setting." Here the students were interested in the setting which they expressed is extremely important to a simulation scenario, in which they felt would be safe. A safe atmosphere can have an immense effect on the scenario and the students. Thirdly, concentration of responses focused on the multidisciplinary nature of the simulation. The participants wrote about the dynamic nature of interacting with students across disciplines. This included recognizing the expertise each discipline brings to the bedside as well as learning how to communicate more effectively.

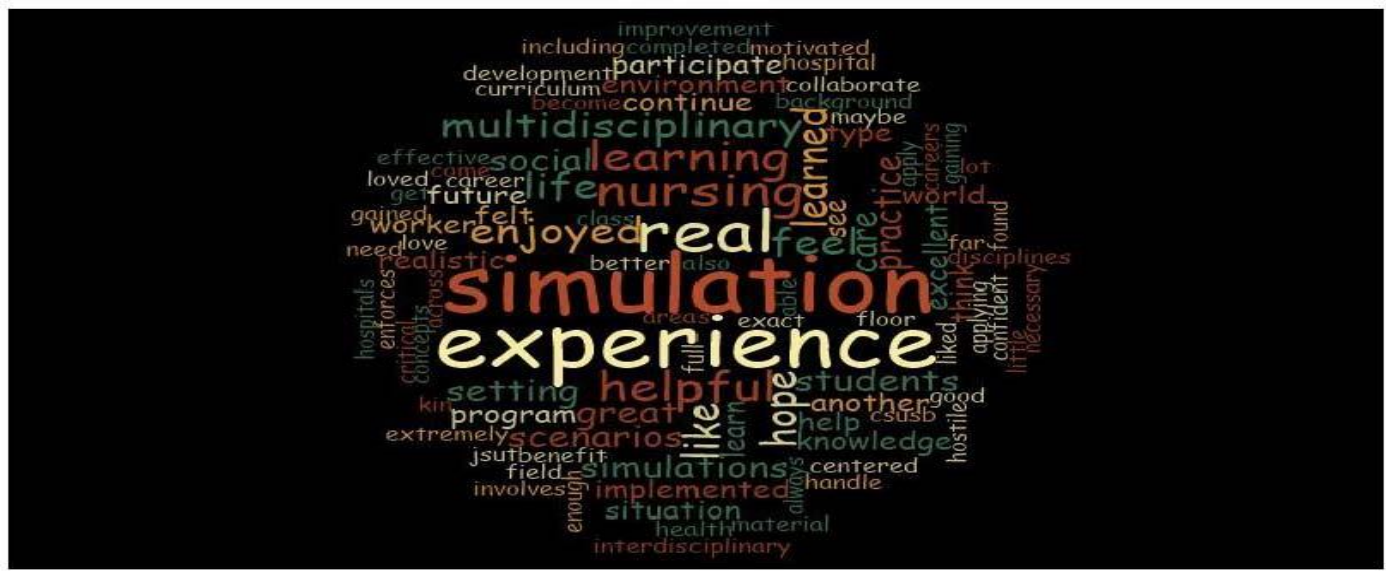

Figure 1. Word cloud of qualitative data from NVivo

The comments from study participants indicate multidisciplinary simulation provides a variety of advantages in terms of effectiveness, interest, confidence, and initiatives in learning. Students appreciated the experience enough that they reported they would encourage other students to participate in future simulation projects. One third of the survey responses recommended more multidisciplinary simulation experiences be conducted.

In response to the quantitative questions, $97.8 \%$ of participants stated that teaching methods were effective in the simulation. All participants agreed that simulation promoted learning and was supported by teaching materials. Forty out of 44 participants enjoyed how instructors taught during the simulation. Forty-three participants agreed that simulation methods supported how they learned, and 42 participants stated that instructors provided helpful resources for simulation activities. With regard to self-confidence in learning, 42 participants stated that they became confident in mastering content and applying what they learned from this multidisciplinary simulation to future clinical settings. According to this study, 43 participants believed that they should be responsible for their learning from simulation activities. 
When it comes to the collaboration among interdisciplinary teams, one-third of participants recommended more multidisciplinary simulation experiences due to the need for and value of collaboration. One-fourth of participants stated that multidisciplinary simulation was realistic as they faced situations with patient care. Some participants now recognized the value of exploring the cultural, religious, and social values of patients as they consider the patient as a whole. This was highlighted by the differing patient care perspectives brought to the simulation activity by other disciplines in this study. Recognition of this concept is valuable when working in a health care system with a diverse workforce as well as diverse patients.

During the multidisciplinary simulation, students can learn effective communication by hearing what each team member does for the patient and what information is vital to their perspective. This also developed mutual trust and respect among team members. According to the study by Maxfield, Grenny, Lavandero, and Groah (2011), mutual trust and respect toward members are essential to the collaboration of interdisciplinary teams. The authors also emphasized communication among interprofessional teams (Maxfield et al., 2011).

This study was conducted using simulation scenarios often seen in clinical settings. A multidisciplinary simulation is not limited to specific clinical settings to achieve targeted outcomes in training health care professionals. Some of the scenarios involved patients outside of the simulation laboratory and moving them safely into beds.

Participants also reported that the simulation experiences helped them apply the theory to actual patient care scenarios. They also reported having more confidence for working with other disciplines after the simulation. They expressed that they now knew how to interact, when to ask for help, and who could provide that help. The students also commented they better understood the chain of command process in health care situations. Students also expressed awareness of their strengths and weaknesses in patient care with plans for areas to improve and strengthen.

Rich (2015) performed interdisciplinary team approach in simulation to reduce intraventricular hemorrhage (IVH) in infants born before 32 weeks gestation by delaying cord clamping (DCC). The simulation team consisted of neonatologists, obstetricians, respiratory therapists, and staff from labor and delivery (L\&D) and the neonatal intensive care unit (NICU). During the simulation, the team completed the process of the DCC step by step by establishing clear communication guidelines, discussing obstacles during births, and setting a specific time frame for the DCC and disseminated a simulation video that led to the great success in the DCC process showing reduced IVH in premature infants (Rich, 2015). Based on information gathered from debriefing and surveys, faculty has identified and plan to implement strategies to improve areas of teaching.

\section{Discussion}

The report from the Institute of Medicine began the conversation about issues in the health care field related to patient safety (Koln, Corrigan, \& Donaldson, 1999). One tool that has proven particularly useful is simulation. A longitudinal multisite simulation study conducted by the National Council of State Boards of Nursing resulted in many reports and guidelines for best practice (Hayden et al, 2014). One stated that up to 50\% of the clinical hours for nursing students could be replaced by simulation experiences that were properly managed (Alexander, et al., 2015). The Agency for Healthcare Research and Quality (AHRQ) funded 11 multi-year research grants in 2011 to help determine best practice (AHRQ, 2011). This included projects that evaluated team performance and communication among team members. A report by the Harvard Medical Institution Risk Management Foundation (CRICO) found that from 23,658 malpractice cases filed from 2009-2013, 7,149 (30\%) were the result of communication failures that caused harm to the patient (The Risk Management Foundation of the Harvard Medical Institutions Incorportated, 2015). These include miscommunication of patient condition, poor documentation, and failure to read the medical record.

It is also emphasized that multidisciplinary care teamwork enhances quality of care. Wong, Caesar, Bandali, Agnew, and Abrams (2009) concluded that multidisciplinary care team approach has improved the communication and coordination of care among the multidisciplinary team of care providers. This approach supported collaboration through mutual awareness, articulation, and continuous management of activities between each care discipline (Wong et al., 2009).

The review by Murphy, Curtis, and McCloughen (2016) showed that multidisciplinary team simulation was effective in improving team performance in the aspects of communication, teamwork, and leadership, leading to a positive impact on patient outcomes. The authors emphasized that multidisciplinary team simulation enhanced team training, specifically resuscitation team training even if they recommended further research be developed to validate team training programs (Murphy, Curtis, \& McCloughen, 2016).

\section{Limitations}

This study has several limitations. The study was conducted with 44 students from one university. The participants in this study were from four different majors: nursing, kinesiology, sociology, and psychology as these were the only health care disciplines available on this campus. Future planning would include more disciplines from more than one 
campus which would increase the number of participants as well. It is recommended that more studies be conducted that include students from various majors and more colleges in order to generalize the study findings.

\section{Acknowledgements}

The team would like to thank California State University San Bernardino for help in funding this study. Funding came from grants from the Student Success Initiative and Vital and Expanded Technologies Initiative. We also want to thank Sonia Perez-Gamboa for the technical assistance she provided during the project. Initial statistical analysis was done by Kahlvia Butler.

\section{References}

Agency for Healthcare Research and Quality. (2011, September). Publications. Retrieved March 30, 2018, from Agency for Healthcare Research and Quality: https://www.ahrq.gov/sites/default/files/publications/files/simulproj11.pdf

Alexander, M., Durham, C., Hooper, J., Jeffries, P., Goldman, N., \& Kardong-Edgren, S., et al. (2015, October). NCSBN Simulation Guidelines for Prelicensure Nursing Programs. Journal of Nursing Regulation, 6(3), 39-42. https://doi.org/10.1016/S2155-8256(15)30783-3

Bradley, P. (2006). The history of simulation in medical education and possible future directions. Medical Education, 254-262. https://doi.org/10.1111/j.1365-2929.2006.02394.x

Bramesfeld, K. D., \& Good, A. (2015). The Game of Social Life: An assessment of a multidimensional poverty simulation. Teaching Sociology; 43, 92-103. https://doi.org/10.1177/0092055X15569316

Brown, J. L. (2015). Using Information Processing Theory to Teach Social Stratification to Pre-Service Teachers. Journal of Education and Learning, 4, 19-23. https://doi.org/10.5539/jel.v4n4p19

Casper, M. J., \& Morrison, D. R. (2010). Medical sociology and technology: Critical engagements. Journal of Health and Social Behavior, 51, 120-S132. https://doi.org/10.1177/0022146510383493

Dorn, D. S. (1989). Simulation games: One more tool on the pedagogical shelf. Teaching Sociology, 17, 1-18. https://doi.org/10.2307/1317920

Fisher, E. M. (2008). USA stratified monopoly: A simulation game about social class stratification. Teaching Sociology, 36, 272-282. https://doi.org/10.1177/0092055X0803600307

Hayden, J., Smiley, R., Alexander, M., Kardong-Edgren, S., \& Jeffries, P. (2014). The NCSBN national simulation study: A longitudinal, randomized, controlled study replacing clinical hours with simulation in prelicensure nursing education. Journal of Nursing Regulation, S1-S64.

IBM Corp. Released 2016. IBM SPSS Statistics for Windows, Version 24.0. Armonk, NY: IBM Corp.

Jeffries, P. R. (Ed.) (2007). Simulation in Nursing Education: From Conceptualization to Evaluation. New York, NY: National League for Nursing.

King, C., \& Cazessus, M. (2014). Teaching with AudaCity: A Board Game for Urban Studies. In European Conference on Games Based Learning, 1, 272-280. Academic Conferences International Limited.

Koln, L. T., Corrigan, J. M., \& Donaldson, M. S. (1999). To err is human. Institute of Medicine. Washington, DC: National Academy Press.

Lovell-Troy, L. A. (1989). Teaching techniques for instructional goals: a partial review of the literature. Teaching Sociology, 17(1), 28-37. https://doi.org/10.2307/1317922

Maxfield, D., Grenny, J., Lavandero, R., \& Groah, L. (2011, September). The silent treatment: Why safety tools and checklists aren't enough. Patient Safety \& Quality Healthcare. Retrieved from https://www.psqh.com/analysis/the-silent-treatment-why-safety-tools-and-checklists-arent-enough/

McNeal, G. J. (2010). Simulation and nursing education. Association of Black Nursing Faculty, 78.

Murphy, M., Curtis, K., \& McCloughen, A. (2016). What is the impact of multidisciplinary team simulation training on team performance and efficiency of patient care? An integrative review. Australian Emergency Nursing Journal, 19(1), 44-53. https://doi.org/10.1016/j.aenj.2015.10.001

Norris, D. R. (2013). Beat the bourgeoisie: A social class inequality and mobility simulation game. Teaching Sociology, 41, 334-345. https://doi.org/10.1177/0092055X13490751

QSR International Pty Ltd. Version 11, 2012.

Rich, D. (2015). Delayed cord clamping: A multidisciplinary Approach. Journal of Obstetric Gynecologic \& Neonatal Nursing, 44(1), 9-10. https://doi.org/10.1111/1552-6909.12670 
The Risk Management Foundation of the Harvard Medical Institutions Incorportated. (2015). Malpractice risks in communication failures. Boston: CRICO strategies.

Wong, H. J., Caesar, M., Bandali, S., Agnew, J., \& Abrams, H. (2009). Electronic inpatient whiteboards: Improving multidisciplinary communication and coordination of care. International Journal of Medical Informatics, 78(4), 239-247. https://doi.org/10.1016/j.ijmedinf.2008.07.012

\section{Copyrights}

Copyright for this article is retained by the author(s), with first publication rights granted to the journal.

This is an open-access article distributed under the terms and conditions of the Creative Commons Attribution license which permits unrestricted use, distribution, and reproduction in any medium, provided the original work is properly cited. 